\title{
Re-Sleeve Gastrectomy for Failed Primary Laparoscopic Sleeve Gastrectomy
}

\author{
Bayrak Mehmet ${ }^{1}$ and Altintas Yasemin 2
}

\begin{abstract}
Objective: To investigate the effectiveness of re-sleeve gastrectomy (LRSG) in patients who had insufficient weight loss or weight regain after laparoscopic sleeve gastrectomy (LSG).

Study Design: Descriptive study.

Place and Duration of Study: Ortadogu Private Hospital, Turkey, between March 2013 and January 2017.

Methodology: Patients who underwent LRSG following LSG due to inadequate weight loss or weight regain retrospectively evaluated. Patients' demographics, comorbidities, and bariatric surgery outcomes, as well as hospitalisation rate, excess weight loss percentage (EWL\%), and body mass index (BMI ) were recorded. Scheduled follow-up visits after surgery at 1, 3, 6, and 12 months post-surgery and every six months subsequently were done.

Results: A total of 21 patients that underwent LRSG after LRG due to inadequate weight loss or a regain in weight. Of them, $7(33.3 \%)$ were males, and $14(66.7 \%)$ were females. The mean body weight index (BMI) before primary LSG was $52.3 \pm 4.7 \mathrm{Kg} / \mathrm{m}^{2}$ and $\mathrm{EWL} \%$ was $32.7 \pm 4.6$. After an average follow-up of 24 months. BMI of patients before LRSG was $46.1 \pm 4.3 \mathrm{Kg} / \mathrm{m}^{2}$. Following a 1-year observation, there was a substantial $(p<0.001)$ improvement in BMI $\left(21.6 \pm 3.1 \mathrm{Kg} / \mathrm{m}^{2}\right)$ and excess weight loss percentage ( $86.82 \%$ of EWL).

Conclusion: LRSG is an available and efficient method to correct the regain of weight or inadequate weight loss following LSG.
\end{abstract}

Key Words: Re-sleeve, Sleeve, Laparoscopic gastrectomy, BMI, Bariatric surgery.

\section{INTRODUCTION}

Morbid obesity is a disease that necessitates a lifestyle change and is diagnosed if an individual has a BMI higher than 40.1,2 Bariatric surgery is an effective therapy; however, some patients respond to the initial procedure, while others only show a partial response. ${ }^{3}$

Laparoscopic sleeve gastrectomy (LSG) is a primary bariatric procedure that is simple, safe, efficient to aid in weight loss, and does not include anastomosis or mesenteric changes. 4

Often, revision of the primary procedure is needed to provide adequate weight loss; therefore, effective therapy is warranted. Recently published reports have shown that treatment of inadequate weight loss after LSG due to a large stomach or dilated/residual fundus can be done using LRSG. ${ }^{5-8}$

The aim of this descriptive study was to investigate the effectiveness of re-sleeve gastrectomy (LRSG) in patients who had insufficient weight loss or weight regain after LSG.

\section{METHODOLOGY}

All patients between March 2013 and January 2017, who had failure to lose weight following LSG, were

Department of General Surgeryl / Radiology², Adana Ozel Ortadogu Hospital, 01360, Turkey

Correspondence: Dr. Bayrak Mehmet, Department of General Surgery, Adana Ozel Ortadogu Hospital, 01360, Turkey

E-mail:drmehmetbayrak@hotmail.com

Received: June 11, 2018; Accepted: September 19, 2018 included in this descriptive study in Ortadogu Private Hospital, Turkey. The inclusion criteria for reoperation were inadequate weight loss $(<40 \%$ of excess weight loss [EWL\%]), progressive regained weight after an initial successful weight loss (defined as EWL $>40 \%$ ) and persistent gastric fundus and/or uniform dilatation and/or antrum dilatation (Figure 1). Exclusion criteria were addictive behaviors such as high sugar grazing and alcohol abuse despite adequate satiety from the first operation.

All patients had a pre-procedure checkup that consisted of assessments by dieticians, internal medicine, psychiatry. Laboratory workup included a complete blood count as well as the examination of renal function, lipids, thyroid, vitamin levels, and $\mathrm{HbA} 1 \mathrm{c}$. All subjects had a pre-procedural abdomen ultrasound, GI X-ray using barium swallow, and endoscopy. Informed consent was obtained from each patient for performing the operation and inclusion in the data collection. Cukurova University, Faculty of Medicine, Clinical Ethical Board approved the study. Written informed consent was obtained from all patients and parents. Data collected comprised patient demographics, comorbidities, current surgery indications, postoperative complications, and the amount of weight reduction.

Any postoperative complications were determined during follow-up. Early hospital readmission was identified as being readmitted to the hospital within the first 30 postoperative days.

LRSG procedure was done with a five-port method. First, dissection between the stomach and liver is carried 
out followed by greater curvature dissection toward the diaphragm (left crus). This was to guarantee fundus mobilisation and visualisation with a LigaSure ${ }^{\mathrm{TM}}$ (Covidien) energy device. A tube was inserted into the stomach by the anesthesiologist using a calibrated $39 \mathrm{~F}$ bougie. First black (Covidien, $6 \mathrm{~mm}$ ) then five purple cartridges (Covidien, $6 \mathrm{~mm}$ ) was used to staple the stomach laterally to the esophagogastric junction. A leak test was done using methylene blue injection. Patients were administered oral fluids initially on day three following confirmation of absence of leakage by upper gastrointestinal series. Patients were then monitored at $1,3,6$, and 12-month intervals.

The statistical analysis of data was performed using SPSS (Version 23.0, SPSS Inc., Chicago, IL, USA) package programme. Categorical measurements were summarised as number and percentage, and continuous measurements were summarised as the mean and standard deviation. Repeated measures analysis of variance was used to test weight changes of patients in time. The statistical significance level was set to 0.05 for all tests.

\section{RESULTS}

The symptoms of LRSG intervention were regaining of weight in $4(19 \%)$ cases and inadequate weight loss in $17(81 \%)$ patients. Twenty-one patients including 7 (33.3\%) men and $14(66.7 \%)$ women, with average age of 37.4 \pm 9.6 (range 21-55) years that underwent LRSG, were registered for this study. LRSG was performed in 21 $(3.3 \%)$ of 620 LSG procedures patients due to insufficient weight loss or weight regain.

The mean body weight index (BMI) before primary LSG was $52.3 \pm 4.7 \mathrm{Kg} / \mathrm{m}^{2}$ and $\mathrm{EWL} \%$ was $32.7 \pm 4.6$ after an average follow-up of 24 months. BMI of patients before LRSG was $46.1 \pm 4.3 \mathrm{Kg} / \mathrm{m}^{2}$. Gastrografin swallow test of the 21 subjects showed upper gastric pouch dilation $(n=14,66.7 \%)$, and/or uniform dilation $(n=7,33.3 \%$, Table I).

Table I: Preoperative patients' characteristics

\begin{tabular}{lc}
\hline & $\begin{array}{c}\text { Mean } \pm \text { SD / } \mathrm{n}(\%) \\
\mathrm{n}=21\end{array}$ \\
\hline Age (years) & $37.4 \pm 9.6$ \\
\hline Pre LSG BMI $\left(\mathrm{kg} / \mathrm{m}^{2}\right)^{*}$ & $52.3 \pm 4.7$ \\
\hline Post LSG EWL \%** & $32.7 \pm 4.7$ \\
\hline Pre LSRG BMI $\left(\mathrm{kg} / \mathrm{m}^{2}\right)^{\star * *}$ & $46.1 \pm 4.3$ \\
\hline Gender & $7(33.3 \%)$ \\
Male & $14(66.7 \%)$ \\
Female & $6(28.6 \%)$ \\
\hline Comorbidities & $4(19.0 \%)$ \\
Blood hypertension & $4(19.0 \%)$ \\
Type 2 diabetes mellitus & \\
Sleep apnea syndrome & $14(66.7 \%)$ \\
\hline Gastrografin swallow & $7(33.3 \%)$ \\
Upper pouch dilatation & \\
Uniform dilatation &
\end{tabular}

*Pre LSG = Before primary LSG; ${ }^{* *}$ Post LSG = After LSG operation (at 24-month)

${ }^{\star * \star}$ Pre $L S R G=$ Before re-sleeve gastrectomy.
The mean $\mathrm{BMI}$, and $\mathrm{EWL} \%$ were $42.1 \mathrm{Kg} / \mathrm{m}^{2}, 19.96 \%$ at 1 month; $35.5 \mathrm{Kg} / \mathrm{m}^{2}$ and $46.89 \%$ at 3 months; 30.1 $\mathrm{Kg} / \mathrm{m}^{2}$ and $68.20 \%$ at 6 months; $24.5 \mathrm{Kg} / \mathrm{m}^{2}$ and $86.82 \%$ at 12 months, respectively (Figures 2 and 3 ).

Some patients with observed comorbidities were shown to improve after LRSG. Hypertension was shown to

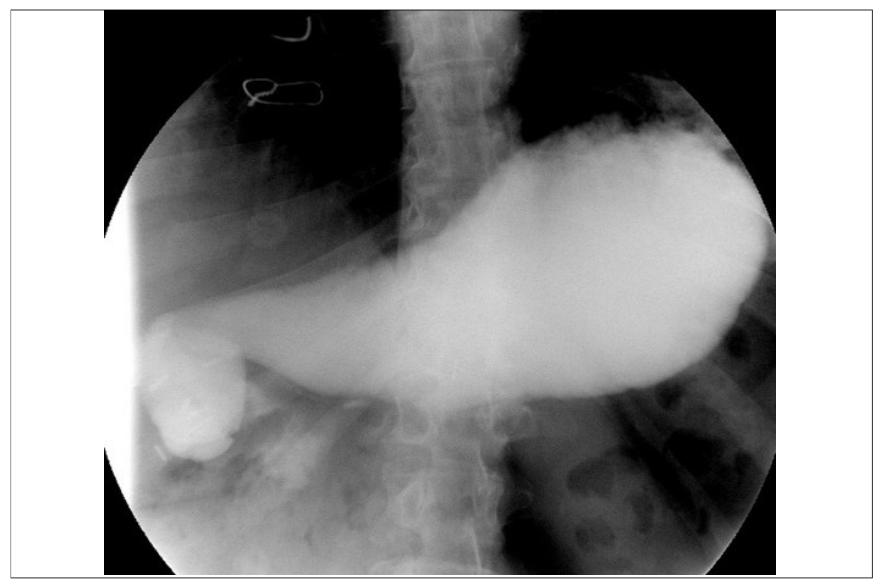

Figure 1: Barium swallow showing dilation of the entire remnant stomach.

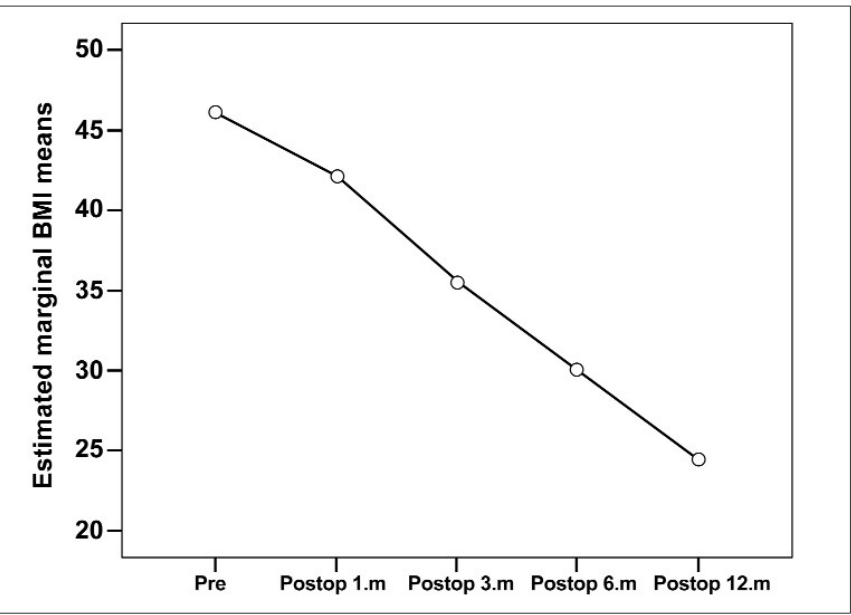

Figure 2: Postoperative BMI after LRSG.

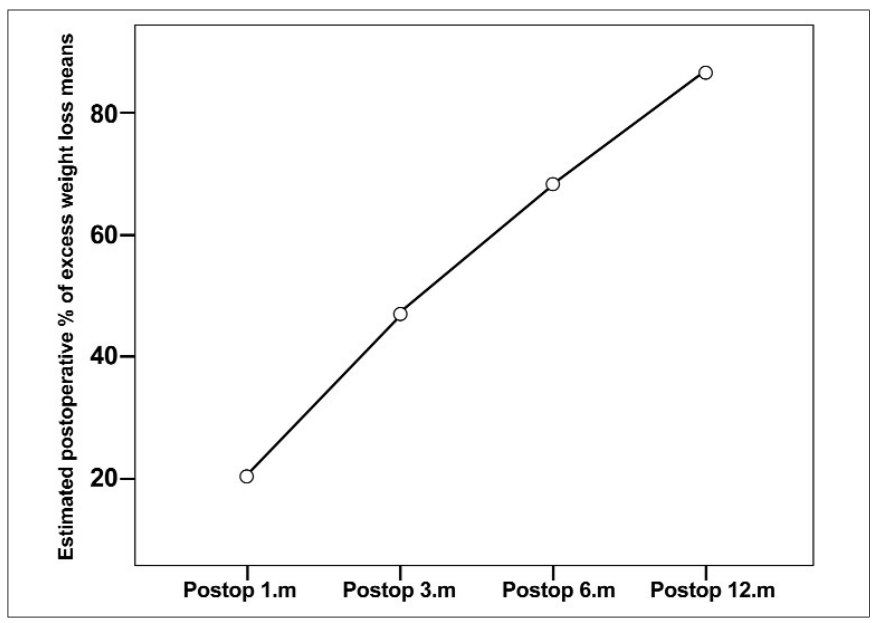

Figure 3: Postoperative \% of excess weight loss after LRSG. 
improve in $50 \%(n=3)$ of the patients and diabetes was reversed in $75 \% \quad(n=3)$ of the patients with this comorbidity. CPAP therapy was withdrawn in three of the four subjects that were diagnosed with SAS.

Postoperative morbidity, vitamin deficiency and dehydration due to inadequate compliance were observed in two patients. Four patients underwent readmission due to postoperative non-specific abdominal pain, which was alleviated via medical therapy. The mean operation time was 48 (range 37-65) minutes, and the average hospitalisation was $3.2 \pm 0.5$ (range 3-5) days.

Figures 1 and 2 show the postoperative BMI, and postoperative percent excess weight loss after LRSG, respectively at the representative follow up visits.

\section{DISCUSSION}

Bariatric surgery is typically successful; however, weight loss, continued disease complications, or weight regain can pose potential issues. Due to this, patients may benefit from subsequent surgery such as LRSG.2

Weight regain after LSG has been documented in several reports.6,9,10 In this study, 21 (3.3\%) out of 620 patients had insufficient weight loss, or weight regain after LSG. An upper gastrointestinal procedure showed a uniform dilatation and gastric fundus (Figure 1).

If LSG fails with weight regain or inadequate weight loss, numerous secondary surgical methods have been proposed for bariatric surgeons.11-14 Evidence has shown that an LRSG is feasible, especially in the absence of a reflux and hiatal hernia and when there is a dilation of the gastric tube.

Cheung et al. showed that both laparoscopic gastric bypass and re-sleeve gastrectomy are viable options for revisional surgery. Both treatments produced similar results; however, LRSG may be more practical due to its less technical challenges. ${ }^{15}$

Cesana et al. performed LRSG operation in 11 patients that gained weight or could not lose enough weight after LSG. As a result of a one year follow up, they detected the improvement in comorbidities and significant weight loss in each patient. 16 There was a significant reduction in weight loss and comorbidities at the 12-month followup after LRSG in 21 patients that gained weight or could not lose enough weight after LSG. Nedelcu et al. found a significant decrease in BMI, excess weight loss, and EWL\% increase during the 1-year follow-up in 61 patients that underwent LRSG operation after LSG. 17 They also detected pouch dilatation in 42 patients and uniform dilatation in the remaining 19 patients. In this study, it was observed pouch dilatation in 14 patients, uniform dilation in seven patients. The cause of dilated antrum and body may be due to dissection further than $6 \mathrm{~cm}$ from the pylorus. The dilated fundus may be caused by dissection further than $1 \mathrm{~cm}$ on the left side of the esophagus. 16
Al Sabah and his colleagues conducted LRSG $(n=24)$ and LRYGB $(n=12)$ (Laparoscopic roux en y gastric bypass) operations as a revision operation for patients who regain weight or insufficient weight loss after primary LSG. ${ }^{18}$ They found that EWL\% of LRSG and LRYGB was 57.6 and $61.3 \%$, respectively in one year. In both groups, a difference in EWL\% recorded insignificant. 18

This study showed that LRSG was a feasible method in all of our patients. Although complications were minimised, vitamin deficiency and dehydration due to inadequate compliance were observed in two patients, and four patients underwent readmission due to postoperative non-specific abdominal pain. Still, LRSG was beneficial for weight loss in all cases. After a 12-month follow-up, there was a significant reduction in mean BMI and an increase in mean \% EWL. The median BMI was less than $25 \mathrm{Kg} / \mathrm{m}^{2}$ following the 12 months. This data also showed that comorbidities were improved after LRSG (sleep apnea in three patients, hypertension in two patients, and diabetes in three patients).

Longer follow-up times are needed to determine the effectiveness of LRSG. Nevertheless, the present data are encouraging in not substituting LSG with a malabsorptive intervention, especially regarding the quality of life.

\section{CONCLUSION}

Weight regain, or inadequate weight loss is a significant undesirable outcome that may occur after LSG. LRSG is a safe procedure which showed significant improvement in weight loss postprocedure and appears to be a beneficial method of correcting post-LSG weight regain or insufficient weight loss.

\section{REFERENCES}

1. Ghoorah K, Campbell P, Kent A, Maznyczka A, Kunadian V. Obesity and cardiovascular outcomes: A review. Eur Heart $J$ Acute Cardiovasc Care 2016; 5:77-85.

2. Pi-Sunyer FX. The medical risks of obesity. Obes Surg 2002; 12(Suppl 1):6S-11S.

3. Brethauer SA, Kothari S, Sudan R, Williams B, English WJ, Brengman $\mathrm{M}$, et al., Systematic review on reoperative bariatric surgery: American Society for Metabolic and Bariatric Surgery Revision Task Force. Surg Obes Relat Dis 2014; 10:952-72.

4. Trastulli S, Desiderio J, Guarino S, Cirocchi R, Scalercio V, Noya G, et al. Laparoscopic sleeve gastrectomy compared with other bariatric surgical procedures: A systematic review of randomized trials. Surg Obes Relat Dis 2013; 9:816-29.

5. Baltasar A, Serra C, Pérez N, Bou R, Bengochea M. Re-sleeve gastrectomy. Obes Surg 2006; 16:1535-8.

6. Himpens J, Dobbeleir J, Peeters G. Long-term results of laparoscopic sleeve gastrectomy for obesity. Ann Surg 2010; 252:319-24.

7. lannelli A, Schneck AS, Noel P, Ben Amor I, Krawczykowski D, Gugenheim J. Re-sleeve gastrectomy for failed laparoscopic 
sleeve gastrectomy: A feasibility study. Obes Surg 2011; 21: 832-5.

8. Noel P, Nedelcu M, Nocca D, Schneck AS, Gugenheim J, lannelli $\mathrm{A}$, et al. Revised sleeve gastrectomy: another option for weight loss failure after sleeve gastrectomy. Surg Endosc 2014; 28:1096-102.

9. Bohdjalian A, Langer FB, Shakeri-Leidenmühler S, Gfrerer L, Ludvik B, Zacherl J, et al. Sleeve gastrectomy as sole and definitive bariatric procedure: 5-year results for weight loss and ghrelin. Obes Surg 2010; 20:535-40.

10. Santoro S. Technical aspects in sleeve gastrectomy. Obes Surg 2007; 17:1534-5.

11. Weiner RA, Theodoridou S, Weiner S, Failure of laparoscopic sleeve gastrectomy - further procedure? Obes Facts 2011; 4 (Suppl 1):42-6.

12. Dapri G, Cadiere GB, Himpens J. Laparoscopic repeat sleeve gastrectomy versus duodenal switch after isolated sleeve gastrectomy for obesity. Surg Obes Relat Dis 2011; 7:38-43.

13. Gagner M, Deitel M, Kalberer TL, Erickson AL, Crosby RD. The second international consensus summit for sleeve gastrectomy, March 19-21, 2009. Surg Obes Relat Dis 2009; 5: 476-85.

14. Regan JP, Inabnet WB, Gagner M, Pomp A. Early experience with two-stage laparoscopic Roux-en-Y gastric bypass as an alternative in the super-super obese patient. Obes Surg 2003; 13:861-4.

15. Cheung D, Switzer NJ, Gill RS, Shi X, Karmali S. Revisional bariatric surgery following failed primary laparoscopic sleeve gastrectomy: a systematic review. Obes Surg 2014; 24: 1757-63.

16. Cesana G, Uccelli M, Ciccarese F, Carrieri D, Castello G, Olmi S. Laparoscopic re-sleeve gastrectomy as a treatment of weight regain after sleeve gastrectomy. World $J$ Gastrointest Surg 2014; 6:101-6.

17. Nedelcu M, Noel P, lannelli A, Gagner M. Revised sleeve gastrectomy (re-sleeve). Surg Obes Relat Dis 2015; 11:1282-8.

18. Al-Sabah S, Alsharqawi N, Almulla A, Akrof S, Alenezi K, Buhaimed $\mathrm{W}$, et al. Approach to poor weight loss after laparoscopic sleeve gastrectomy: Re-sleeve versus gastric bypass. Obes Surg 2016; 26:2302-7.

....々..... 